\title{
El humor y la revisión del mito en la obra teatral Penelopeide de Patrizia Monaco*
}

\author{
Milagro Martín-Clavijo**
}

\begin{abstract}
Resumen
En los últimos años la dramaturga italiana Patrizia Monaco se ha servido del humor para presentar al público una mirada diferente y crítica sobre varios mitos conectándolos con temáticas actuales de interés social. En este artículo se estudia la obra teatral Penelopeide (2008) teniendo en cuenta las características de la revisión del mito a través del humor propias de la edad postmoderna. De esta manera, se analiza el tratamiento irónico/paródico de lo heroico y la yuxtaposición de voces, espacios y tiempos para llegar a la construcción de una identidad femenina diferente, la de Penélope, que subvierte el pensamiento dominante y se presenta en primera persona.
\end{abstract}

Palabras clave: Patrizia Monaco, Penelopeide, Revisión del mito, Humor subversivo.

\footnotetext{
* Recibido el 29 febrero 2020, aceptado el 12 mayo 2021.

** Profesora Titular, Universidad de Salamanca, Salamanca, España. mclavijo@usal.es / http://orcid.org/0000-0001-73009493 
Humor and the Revision of Myth in Patrizia Monaco's Play Penelopeide

\begin{abstract}
In recent years, Italian playwright Patrizia Monaco has used humor to present to the public a different and critical view of various myths, linking them to current themes of social interest. This article studies the play Penelopeide (2008), considering the characteristics of the revision of myth through humor typical of the postmodern age. It analyses the ironic/parodic treatment of the heroic and the juxtaposition of voices, spaces and times to arrive at the construction of a different female identity, that of Penelope, which subverts dominant thinking and is presented in the first person.
\end{abstract}

Keywords: Patrizia Monaco, Penelopeide, Revising Myths, Subversive Humor 


\section{Mito y vena humorística en la edad postmoderna}

La dramaturga italiana Patrizia Monaco se acerca a la compleja realidad que le rodea con grandes dosis de humorismo propio, como señala Lipovetsky (1986:137), de una sociedad postmoderna que no es proclive al drama, sino más bien a algún tipo de expresión humorística, ya que la ausencia de fe, de certezas, "el neo-nihilismo que se va configurando no es atea (sic) ni mortífera, se ha vuelto humorística". Estamos en la era en la que el afán de coherencia y de simplificación ya no es viable; no se puede reducir la complejidad de la realidad ya que esta no es compacta, como tampoco lo pueden ser las historias que se cuentan. Ahora, ante la ausencia de una explicación sólida, todo es objeto de risa y es por ello que se recurre tan frecuentemente al discurso impregnado de ironía o de parodia. De ahí que resulte natural la construcción de espacios mentales múltiples donde se revisen estas verdades que durante siglos se han estimado inamovibles e incuestionables, aunque puedan vehicular contenidos erróneos, contradictorios o discriminatorios. De esta manera, con los instrumentos cómicos se relativiza todo lo que se ha considerado fijo y se rompe con la uniformidad de pensamiento.

Es verdad que el humorismo no es la única manera de construir estos lugares mentales abiertos a través de la disonancia cognitiva, pero se ha probado que su uso puede resultar muy eficaz, sobre todo si tenemos en cuenta al público al que nos dirigimos y ante el cual se presentan creencias arraigadas ahora privadas de consistencia. El humor presenta cambios, a veces sustanciales, en nuestros marcos de referencia, lo que puede provocar que uno se sienta incómodo, desconcertado si se le fuerza en otra dirección de forma abrupta; por eso, hay que tener en cuenta la reacción del público. Además, a través del humor se rehúye la protesta directa, que puede resultar ofensiva, y se opta por una vía trasversal que lleve a la toma de conciencia sobre aspectos que muchas veces tienen que ver con nuestra identidad personal y/o colectiva. Es verdad que el modo cómico no es capaz de cambiar algunos aspectos de la realidad, pero sí consigue ir abriendo mentes para que, en un segundo momento, se pueda producir tal cambio. El humorismo, a través de la sorpresa y la variación de perspectiva, pero también gracias al deleite que proporciona al público, ayuda a salir de unos parámetros cognitivos fijos. De hecho, se puede convertir en una forma de resistencia ${ }^{1}$ ante lo considerado como absoluto: instituciones, poderes y convenciones que una determinada sociedad impone al individuo y que este interioriza a veces tanto que ni siquiera es consciente de ello².

A través del humorismo se pone en duda todo lo que nos rodea, hasta las historias mitológicas. Por tanto, la revisitación del mito se puede considerar también como un diálogo entre distintas actualizaciones del mismo, lo que supone, por un lado, el mantenimiento de ciertos elementos constitutivos y, por otro, la transformación, cancelación o introducción de otros nuevos. De esta manera, como afirma Chauvin (2005), el mito funciona como un intertexto que genera nuevos textos que, en última instancia, ratifican que este sigue vivo, que sigue hablando del ser humano y todavía hoy puede comunicar. Evidentemente, esa nueva visión del mito parte de una intencionalidad que puede ser muy distinta a la del original. Si nos referimos, además, a una presentación irónica del mito podemos hablar de una subversión del mensaje mítico, de un distanciamiento $^{3}$ del original que no se lleva a cabo nunca de manera ingenua ${ }^{4}$ :

\footnotetext{
1 Para Berger (1997) este humor como forma de resistencia ante las convenciones e instituciones sociales se da frecuentemente entre personas que, de alguna manera, se encuentran en la periferia de la sociedad, como les ocurre a las mujeres. Sobre la risa contra el patriarcado véase el artículo de Billingsley (2013).

2 Desde el feminismo se ha abordado el humor y se han tomado en consideración también los aspectos sociales y políticos. Sobre las mujeres y el espacio de resistencia que provee el humor véase Irigaray (1985 y 1993) y Cixous (1981 y 1995).

${ }^{3}$ Linda Hutcheon (1989:8) también señala las razones para este tratamiento distanciado respecto de lo normativo desde una perspectiva posmoderna: "On the one hand, there is a sense that we can never get from under the weight of a long tradition of visual and narrative representations and, on the other hand, we also see to be losing faith in both the inexhaustibility and the power of those existing representation. And parody is often the postmodern form this particular paradox takes".
} 
El mito ironizado nos indica cómo la modernidad puede recontar el viejo relato con sorna y escepticismo extremados, no solo con el fin de expresar la enorme distancia en que el escritor se sitúa ante el relato heroico, sino también para contrastar el viejo texto mítico y sus sombras en un mundo próximo (Ochoa, 2003:25).

Ya que el mito transmite imágenes y estereotipos bien arraigados, revisitarlo con ironía significa ponerlo en duda, cuestionarlo de distintas maneras. Esta subversión también la llevan a cabo las escritoras que "retoman algunos de los motivos conocidos de la tradición literaria con el objetivo de aclarar y rectificar el silencio previo y, en consecuencia, modificar la percepción que de los mitos de mujer se ha mantenido hasta nuestros días" (Gómez Jiménez, 2012:100). De hecho, este es uno de los filones más explotados por muchas escritoras a nivel internacional que tienen la intención de actualizar los modelos de conducta generalizados y hacer de los héroes y heroínas seres más humanos y cercanos al hombre actual. Con sus obras ofrecen, por tanto, una perspectiva diferente, divergente, múltiple, que deja en evidencia algunas contradicciones inherentes al mito clásico. Estas autoras, entre las que se encuentra Patrizia Monaco, toman distancia de los discursos estáticos que se han transmitido durante siglos y colaboran a una apertura de perspectiva que va a ser, por un lado, la de la mujer $-y$, muchas veces, muy cercanas a las ideas feministas $-y$, por otro, desde una concepción donde la historia, la sociología, la psicología, la antropología, y otras ciencias tienen mucho que aportar. De esta manera, se produce una ruptura evidente con la tradición patriarcal, considerada como la única posible y se pone en entredicho el valor legitimador de dichos textos canónicos.

\section{Humor y mito en el teatro de Patrizia Monaco}

Patrizia Monaco ${ }^{5}$ es una dramaturga italiana que destaca por su compromiso social, su experimentación ${ }^{6}$ y una perspectiva diferente sobre lo que la rodea. Desde 1978 hasta hoy hay publicado numerosas obras ${ }^{7}$ que atestiguan la carrera regular y prolífica de la escritora, algunas de matriz histórica - Il vero e il falso O'Brien, Una vertigine sopra l'abisso o La strada verso il cielo-, literaria - Goldoni a Genova - o mítica, como veremos. A lo largo de su trayectoria, tanto en Italia como en el extranjero, ha recibido numerosos y prestigiosos premios como el Riccione, Idi, Vallecorsi, Fersen, Donne e Teatro o el Anticoli Corrado.

$\mathrm{El}$ interés de Monaco por el mito y por el humor viene desde muy atrás. Si comenzamos por la fuerte atracción de la autora por la mitología, nos encontramos con un alto número de obras en las que se revisitan temas y personajes mitológicos, de forma crítica y vinculándolos siempre a temáticas de gran actualidad. Como afirma el estudioso Roberto Trovato (2016a:360), con estas obras la autora tiene el mérito de "innescare un risveglio di coscienza civile in un pubblico che stava intorpidendosi" sirviéndose de materiales muy presentes en el imaginario colectivo para acercarse a ellos desde una perspectiva nueva e intentar así llegar a una verdad que no sea absoluta. De hecho, la propia autora en la nota a Penelopeide cita a Jean Cocteau: "Ho sempre preferito la mitologia alla storia, perché la storia è una verità che di bocca in bocca si deforma e diventa menzogna, mentre il mito, di bocca in bocca, prende forza e diventa verità" (Monaco 2016:101). De esta manera, en busca de una verdad alternativa, adquieren fuerza obras como Condominio mitológico 8 en la que se incluyen también dos monólogos escritos con anterioridad Ares, la penúltima verità e Icaro 2001. Estos espectáculos surgen a raíz de la investigación que llevó a cabo la autora sobre

\footnotetext{
4 En este sentido, las palabras de Umberto Eco (2010:770) son claras: "La respuesta posmoderna a lo moderno consiste en reconocer que, puesto que el pasado no puede destruirse - su destrucción conduce al silencio -, lo que hay que hacer es volver a visitarlo; con ironía, sin ingenuidad".

5 Sobre Patrizia Monaco y su producción dramática en general véase Martín-Clavijo (2016b, 2017a) y Trovato (2012, 2016b).

6 Sobre este aspecto, véase Trovato (2014:1-2).

7 Entre ellas señalamos: L'Aquilone, Pagliacci, Estate a Casa Magni, Cellulite Addio, Se il futuro è così, io non vengo...., Donne Africane, Tutto per non aver mangiato i cavoletti di Bruxelles, Giustizia in diretta, Clarinett, L'occasione, Fatal Love, Gengis Khan, Ė tutto vero ma non è laverità y Fuoco!!!!

8 Sobre esta obra se vea el estudio realizado por Trovato (2016a).
} 
algunos mitos y sobre la mitocrítica y, especialmente, como declara en una entrevista concedida a Roberto Trovato (2016a:352), con la lectura de Il potere del mito de Joseph Campbell. En efecto, del poder de mito se sirve Monaco para contar el presente, especialmente cuando este se encuentra rodeado de polémica y dolor. De los últimos años son las revisiones del mito en Pandora, la prima donna y Atargatis.

Por lo que se refiere al uso del humor en su dramaturgia, hay que destacar que, desde sus comienzos, sus obras se caracterizan por "la vena comica e brillante, coniugata con quella satirica $e$ grottesca" (Trovato, 2016b:24) con la que consigue equilibrar la fuerte crítica y la denuncia que vehiculan sus textos. En los estudios que se han realizado sobre su producción dramática se ha destacado la importancia del humor: "l'umorismo, l'ironia - in certi passi ti pare di sentire una risata divertita o dolorosa - le permettono di rovesciare i fatti, di variare le prospettive, di ipotizzare differenti soluzioni possibili" (Sandias, 2017:12). Ese cambio de perspectiva que aporta el humor es del que se vale también en algunas de las obras en las que trabaja sobre el mito. De hecho, en Atargatis y Pandora, la prima donna9 Monaco lleva a cabo una "rivisitazione ironica e fantasiosa di alcuni dei più noti miti della letteratura occidentale" ${ }^{10}$ para afrontar temáticas como la inmigración o la injusticia. Con esa vena humorista se afrontan estereotipos y clichés culturales como en Sherazade va in Occidente, llevada a escena en 2002, cuyos cinco actos únicos "comico-brillanti, satirici e umoristici" (Trovato, 2014:2) se centran en la representación de las odaliscas.

\section{Humor subversivo y la presentación de otra Penélope en Penelopeide ${ }^{11}$}

¿Qué idea de mujer se nos ha transmitido de Penélope a través del relato homérico? ${ }^{12}$ La de una mujer fiel, paciente, cuya vida gira alrededor de su familia por la que se sacrifica renunciando a todo lo personal y que se dedica a las labores propias del sexo, como tejer y bordar. La mujer de Ulises, como ella misma afirma en la obra de Monaco, gracias a la versión que se ha afirmado en el mundo, "la versione ufficiale dell' Odissea, quella dalla parte di Ulisse" (Monaco, 2016:103), se ha convertido en "una leggenda edificante. Un bastone per picchiare le altre donne" (Monaco, 2016:104). Ya en estas palabras nos encontramos la base sobre la que va a actuar la dramaturga de Liguria, esa versión de los hechos trae consigo un modelo concreto de mujer, único y legitimado por la sociedad ${ }^{13}$, pero muy lejano de la visión actual de mujer independiente que busca realizarse en todos los aspectos. A Penélope, tres mil años después y desde el Hades, no le gusta el papel que le ha dado la historia; ya es tiempo de romper con su silencio y dejar que su punto de vista salga finalmente a la luz. Ya desde el primer momento se nos presenta con toda su carga de humor subversivo provocando a las otras mujeres: "Non potete essere fedeli come Penelope? Lei ha aspettato venti anni suo marito, venti, mentre voi, quando il vostro va due giorni a Biella per lavoro vi sentite autorizzate a tradirlo col postino!" (Monaco, 2016:104). No son tiempos los actuales para la espera pasiva de la mujer, pero, como afirma la protagonista a lo largo de la obra, tampoco lo era

\footnotetext{
9 Trovato (2017) ha realizado un estudio sobre estas dos obras.

${ }^{10}$ Así se señala en la motivación para la entrega de la Targa Poggiani del Premio Calcante de la revista Ridotto en 2016 por Atargatis. Citado en Trovato (2017:111).

${ }^{11}$ Para el análisis de la Penelopeide de Patriza Monaco que se lleva a cabo en esta sede se parte de la última edición que se ha hecho de la obra y que aparece en el volumen Donne in lotta, junto a Il vero e il falso O'Brien y La strada verso il cielo (Monaco, 2016). Por lo que se refiere al espectáculo, la primera representación es en julio de 2008 en el Teatrino Strehler de Portofino con la producción de La Perla del Tigullio Teatro y la dirección de Fabrizio Lopresti. Penelopeide cuenta con otras representaciones entre las que se destaca la del Festival Teatro delle Donne en Portovenere, 2008. Con esta obra Monaco ha recibido distintos reconocimientos en 2009, el Premio Fara Nume, secondo classificato, el Premio Letterario Nazionale "Lago Gerundo", Dramma del mese di settembre 2009 en la revista dramma.it. Para un análisis de esta obra cfr. Martín-Clavijo (2016a, 2017b y 2018).

${ }^{12}$ Sobre esta figura mítica en general véase Mactoux (1975) y Katz (1991). En concreto, sobre Penélope y Ulises en el teatro es interesante el estudio de García Romero (1997).

${ }^{13}$ Desde el feminismo se señala que esos modelos de mujer no se dan en el vacío, sino que están determinados por un contexto político, social, económico y cultural y este cambia en el tiempo y en el espacio. Por ello, como bien señala Piscitelli en su estudio titulado "Re-criando a (categoria) mulher?" (2002:20), se ha reivindicado la necesidad de comprender los contextos específicos en los que el sistema sexo/género aparece. Esto es lo que también lleva a cabo Monaco en esta obra.
} 
en los tiempos de Homero. La nueva Penélope parte así de lo esperado para proseguir luego en direcciones inesperadas y perturbadoras gracias al humor. La risa, como ya lo anunciaba Hélène Cixous (1995), es fundamental para la afirmación del discurso femenino fuera de los límites totalizadores de los hombres.

Monaco, junto a otros muchos escritores y escritoras ${ }^{14}$ en todos los géneros literarios, va a revisitar el mito de Penélope y, para ello, tendrá también que reformular necesariamente el de Ulises. En primer lugar, se la revela de su papel secundario y se le da un espacio propio y privilegiado, el de protagonista de su propia historia. El foco de atención es, por tanto, Penélope y el título ya es ilustrativo: en Penelopeide se nos narra la epopeya de Penélope, las hazañas legendarias de un personaje heroico. Esto se va a llevar a cabo cambiando radicalmente el punto de vista, lo que convierte a Penélope no en objeto, sino en sujeto de narración; ya no es un personaje marginal del texto homérico, siempre a la sombra de Ulises, siempre en función de unos determinados intereses patriarcales. Después de muchos años de silencio llega el momento de contar su historia y romper el silencio que es una manera también de liberarse. De hecho, ya en la primera acotación, Monaco nos presenta una especie de danza de la protagonista con la Bailarina que representa también a Elena ${ }^{15}$-, en la que esta última intenta atraparla y cubrirla con un velo. Penélope se libra físicamente de él, como también de una manera caduca de pensar, de ver el mundo y, en concreto, del mito en el que ocupa un lugar secundario. En esta reinterpretación se tendrán en cuenta múltiples aspectos, tanto históricos como sociales, económicos y culturales ${ }^{16}$ que van a hacer saltar las incongruencias y las contradicciones inherentes al mito ${ }^{17}$.

A través de una nueva Penélope que se sirve del humor para subvertir el mito se abre un proceso dialógico evidente, una polifonía de voces, de miradas, de interpretaciones que obligan a nuevos planteamientos, a una apertura en la manera de ver la realidad, un cuestionamiento crítico y serio de los estereotipos para hombres y mujeres que tenemos interiorizados; además, se pone en tela de juicio las instituciones que han ido manteniendo a lo largo de los siglos esa mentalidad patriarcal basada en la discriminación. En este proceso dialógico se ponen en juego, como veremos también, los códigos de identidad.

\section{Yuxtaposición de voces, espacios y tiempos}

\section{En la nota inicial a Penelopeide Patrizia Monaco señala:}

Il testo è costituito prevalentemente da una serie di monologhi contrapposti e incrociati.

Non c'è azione sulla scena, se non per le coreografie e piccoli gesti, il movimento è dato all'interno delle battute che provengono simultaneamente dall'Ade e da Itaca. Infatti, i due personaggi Penelope ed Euriclea sono contemporaneamente ora nell'Ade e allora ad Itaca.

Si parlano ma è come non interagissero mai direttamente (Monaco, 2016:101).

Ya en estas primeras líneas la dramaturga nos deja claros varios aspectos cruciales de su espectáculo. En primer lugar, aunque en escena se encuentren siempre dos personajes, Penélope y

\footnotetext{
${ }^{14}$ En este sentido, en lengua española véase para la narrativa la antología de Brigidina Gentile (2011) y para el teatro Carmen Resino, Ulises no vuelve, 1973-1981; Las voces de Penélope, 1996, de Itziar Pascual; Polifonía, 2001, de Diana de Paco Serrano o Soy Ulises, estoy llegando, 2007, de Ainhoa Amestoy. En ámbito italiano cabe destacar en teatro Io sono Penelope de Fabrizio Lo Preti y Penelope tesseva e Nessuno la filava de Giulio Manfredi. Este tema ha interesado también a narradoras italianas como Oriana Fallaci con la novela Penelope alla guerra (1962).

${ }^{15} \mathrm{~A}$ lo largo de la obra la protagonista reitera un profundo antagonismo con su prima Elena fundamentalmente por su centralidad en el origen del relato homérico. Por eso, es interesante que, al principio de la obra, sea precisamente ella la que la envuelva con un velo, la que la intente privar de movimiento, de visibilidad, de voz y también es ciertamente indicativo que se consiga librar ya desde ese momento. Ese velo se convierte casi en un símbolo del silencio, de la fuerza con la que se ha impuesto una sola manera de contar una historia.

${ }^{16}$ En este sentido cfr. Lasso de la Vega (1989) y Morano (1982).

${ }^{17}$ Hyers (1996:86) se refiere a la risa del paraíso reconquistado, en el sentido de una apertura de mente que saca a la luz las contradicciones del sistema patriarcal y destruye sus mitos. De esta manera, se puede avanzar hacia una variedad de identidades con las que podernos identificar. En Penelopeide Patrizia Monaco se interroga sobre la categoría "mujer", cuestión muy debatida en ámbito feminista. Sobre las posibilidades analíticas de esta categoría y su evolución en las últimas décadas, véase Adriana Piscitelli (2002).
} 
la criada Euriclea, no hay comunicación posible entre ellas; de hecho, se trata de monólogos que no se encuentran, que no van en la misma dirección, como si cada una hablara consigo misma y no con la otra; es más, ignorándose recíprocamente. Estas indicaciones son necesarias porque las dos protagonistas serán portadoras de ideas diferentes del mito que entran en una contraposición imposible de evitar, ya que no pueden convivir dos interpretaciones tan dispares de la misma historia $^{18}$. Conscientemente, Monaco no sitúa a las dos protagonistas en situación de diálogo, deja que cada una exprese su punto de vista y que sea el lector/espectador el que saque sus propias conclusiones.

Esta técnica de montaje por yuxtaposición se ve reforzada por dos aspectos que la autora marca desde el principio: existen dos espacios narrativos claros, Ítaca - la isla donde se sitúa el reino de Ulises - y Hades - el inframundo de los griegos -, así como dos tiempos, el que nos lleva al mito oficial de Homero y el actual. De esta manera, se marca explícitamente la distancia que separa a las dos narradoras en escena, pero también la manera de pensar de cada una de ellas en un momento distinto de la historia. Así, accedemos a versiones distintas a partir de una distancia ideológica del mito oficial que corresponde a un tiempo diferente (han pasado 3.000 años, como afirma Penélope en la primera escena) y a un espacio distinto (ya no la Ítaca, sino el Hades, el reino de los muertos). Esta distancia desde la que acceder a la realidad es muy necesaria para el humor como método para acceder a la realidad desde otro punto de vista, desde un ángulo diferente al habitual.

Si esta nueva perspectiva para enfrentarse a un mito homérico completamente arraigado en la sociedad puede producir la risa es, en buena parte, porque desde el personaje se establece un distanciamiento con la realidad. Por eso, como veremos, toda la carga subversiva de Penélope con respecto a la versión que del mito ha presentado Homero se hace fundamentalmente desde el Hades, es decir, desde una clara conciencia del paso del tiempo, del cambio de mentalidad en la sociedad y desde un conocimiento más profundo y activo de la realidad que nos rodea ${ }^{19}$. En la obra, la dramaturga lo marca con acotaciones claras en las que señala el "tono de Hades", es decir, fuertemente irónico, frente al "tono de Ítaca", serio y respetuoso con la tradición. Este tono de Ítaca revela, si usamos los términos de Ziv (1983:72), un pensamiento creativo, divergente ${ }^{20}$ : "Humor, like play, is an invitation to fantasy...", y conduce a un pensamiento libre de las limitaciones impuestas por otros, a una apertura a la complejidad de la realidad y a nuevas vías de pensamiento, de cuestionamiento de expectativas de todo tipo, de costumbres, normas, reglas y puntos de vista hegemónicos. Un humor que, además, sirve para legitimar dicho pensamiento creativo.

Se produce, por tanto, un extrañamiento de la realidad, casi como si Penélope, desde el conocimiento que le otorga el tiempo y la distancia, se comportara como una antropóloga que, desde posiciones científicas y muy actuales, observa y analiza críticamente, sin un ápice de sentimentalismo, los elementos basilares del mito de la Odisea y, en especial, los que tienen relación directa con ella. Y lo hace sin sensiblerías, sin dulcificar la realidad, desde lo que Dolores Juliano (2004:70) ha definido como "distancia respetuosa" 21.

Por tanto, en Penelopeide nos encontramos con dos voces muy diferentes en la escena, la de Penélope y la de Euriclea, que, además, se mueven continuamente entre dos espacios y tiempos distintos, lo que hace que la polifonía sea todavía mayor. En Inside Jokes: Using Humor to ReverseEngineer the Mind los autores ya remarcan que:

\footnotetext{
${ }^{18}$ De hecho, con el humor se otorga a unos personajes la sensatez, el sentido común, y a otros el disparate, la mirada no civilizada.

${ }^{19}$ Este cambio perspectiva tanto en el tiempo como en el espacio que es central en Penelopeide se puede relacionar con la teoría de Judith Butler sobre el género en Deshacer el género (2006): por un lado, la repetición a lo largo de los siglos aporta al género estabilidad y norma, pero también, al desarrollarse en un contexto concreto, al cambiar este se permite su cuestionamiento, su subversión, su construcción de manera diferente.

${ }^{20}$ Por su parte, John Monreall (2009:116-117) subraya el rasgo distintivo más importante entre "seriousness" y "playfulness", la apertura de este último hacia lo diferente y lo complejo, un paso de "divergente thinking" a "convergente thinking" (Morreall 1999:32).

${ }^{21}$ Morreall (2009) también señala que esta apertura mental a la que nos lleva el humor nos hace más tolerantes ante lo diferente.
} 
simple temporal juxtaposition - getting both beliefs active at the same time - is the necessary first step in the creation of conflict between two or more beliefs in active memory - they can be contradictory and side by side in long term for a long time - dormant" (Hurley et al., 2011:113).

El conflicto se lleva a escena con este juego de tiempos y espacios y con una clara antipatía entre las dos protagonistas, por eso no hay interacción entre ellas, simplemente están en escena simultáneamente representando versiones de Penélope y de Ulises muy diferentes entre sí. Estamos ante un claro y continuo desdoblamiento de la conciencia. Esta división temporal lleva a su vez a una distancia en la forma de hablar de las protagonistas, con lo que también desde el punto de vista lingüístico se evidencian identidades divergentes. Por un lado, asistimos al mito tal y como se ha fijado en el imaginario colectivo desde Homero y, como dice Penélope, desde el punto de vista de Ulises y, por otro, la reelaboración que se lleva a cabo de la imagen de la esposa de Odiseo, ahora completamente alejada del estereotipo femenino presentado en la épica y claramente más cercano a la idea que tenemos de la mujer en el siglo XXI. De esta manera, "los tiempos pasados se actualizan sobreimponiéndoles una evaluación presente, descubriendo en ellos la raíz del comportamiento actual" (Ciplijauskaité, 1994:208) y enfatizando, además, distintas posibilidades de construcción de la identidad femenina que no es fija, sino múltiple y susceptible de cambio. A través de la distancia temporal se está presentando una actualización del arquetipo femenino.

De cualquiera de las maneras, este desdoblamiento de tiempos y espacios en escena hace que en algunos momentos la narración esté fuertemente fragmentada, especialmente cuando se yuxtapone en la misma frase la narración clásica de los hechos y la interpretación irónica, como es evidente en la exposición de la protagonista de su historia cuando era una niña:

Quando ero bambina mio padre ordinò che fossi gettata in mare. La solita faccenda degli oracoli. Gli avevano predetto che avrei tessuto il suo sudario. Un po' ingenuamente, avrà pensato che se mi impediva di farlo, lui non sarebbe mai morto... Ma il sudario non era il suo. Lo capimmo più tardi. Gli oracoli si esprimono volutamente in maniera ambigua.Tutto per divertirsi alle spalle degli umani. Mio padre, comunque, ci cascò. Ma avrete già capito che doveva essere proprio un imbecille, se provò ad annegare la figlia di una naiade!!! (Monaco, 2016:106) ${ }^{22}$.

\section{Tratamiento irónico/paródico de lo heroico en Penelopeide}

Penélope, a través de un discurso fuertemente irónico y, en muchos sentidos, en las antípodas de la versión homérica, desafía a Ulises y se enfrenta de ese modo a la tradición. A través de sus palabras se va deconstruyendo la imagen heroica de Odiseo, fundamentalmente porque ahora la posición privilegiada de la narración la ocupa Penélope; desde la distancia temporal y espacial, el héroe griego se nos presenta principalmente como un hombre, con sus debilidades, con sus sentimientos, con sus errores y sus hazañas se convierten en algunas ocasiones en aventuras privadas de toda legitimación y función social. Se trata de una nueva lectura paródica e irónica del mito homérico en la que, como afirma López López (2014:89) en relación a una reelaboración teatral del mito de Circe, "la parodia adviene como rebajamiento de la fisonomía y el carácter elevado con que se perfilaban los héroes en la epopeya homérica". De hecho, ya hay un primer aspecto que salta a la vista y que subraya la protagonista desde el comienzo del espectáculo: ¿quién en la época actual podría considerar a Ulises un modelo de marido?

Cuando se desmitifica un determinado mito, cuando se parodia un relato mitológico y se desestabiliza un texto canónico determinado, se rebaja también el patrón de conducta que este transmite. A través del humor se produce un efecto desacralizador $y$, por tanto, se abre una puerta a una manera diferente de conocimiento, libre de prejuicios y tabúes, muy alejado del conocimiento sagrado, inamovible y poco susceptible de crítica. Esta desvalorización de los sistemas que están asentados en nuestra sociedad o en las instituciones que la integran provocan la risa inicial y, sobre todo, nos obligan a una reflexión sobre las ideas que tenemos interiorizadas. Con la inversión de la

\footnotetext{
${ }^{22}$ El cursivo para señalar la ironía es mío.
} 
lógica "normal", se arremete contra todo orden jerárquico y autoridad y también se destruye todo lo que los sustenta.

Un ejemplo muy claro en la obra lo tenemos cuando se tratan las razones para la guerra de Troya:

PENELOPE- Un anno dicevano che sarebbe durata quella guerra. (Pausa breve) E certo non fu per un paio di corna.

EURICLEA- Tanto va la gatta al lardo...

PENELOPE- Troia (Si interrompe guardando il pubblico) ...niente facili allusioni, vi prego! Troia era sulle rotte commerciali utili ai greci. Troia era un bocconcino ghiotto. Anche mia cugina era... un bocconcino ghiotto (Monaco, 2016:112).

¿Cuál fue la verdadera causa de la guerra de Troya? ¿Quién podría hoy en día acusar a Elena? Como vemos, Patrizia Monaco trabaja para deconstruir verdades institucionalizadas a través del mito, para devolver a la realidad su complejidad y desnudarla de todo barniz simplicista, pero también desmonta de manera sistemática los mecanismos de un aparato que casi todo el mundo considera eficaz. La dramaturga elige ciertos pasajes del texto homérico, los combina con otras tantas versiones del mito y les permite que conversen entre sí, teniendo bien en cuenta que este diálogo intertextual puede desacreditar el texto de partida.

Otras veces Monaco retoma estos pasajes, pero para deformarlos, para vaciarlos de su contenido original. La parodia cumple una función clara, la de revelar el engaño al que ha sido sometido el ser humano, la de iluminar los aspectos contradictorios ${ }^{23}$. A través de la parodia la autora toma distancias del texto del que se parte y establece con él un diálogo contrastivo. Por un lado, está la parte seria, la del significado original, que en Penelopeide está representada fundamentalmente por Euriclea y, por otra, la parte paródica, la versión de Penélope. De esta manera, se formula de manera definitiva una idea para destruirla por completo, para que, a partir de ese momento, ese concepto no pueda volver a tomarse en serio. ¿Cómo tomar en serio a Ulises y todas las historias narradas en la Odisea después de las palabras de Penélope?

Evidentemente, en toda parodia es necesaria la competencia literaria ${ }^{24}$ del lector/público para poder entenderla, para poder apreciar los ecos intertextuales que se dan en el espectáculo. Como cada uno tiene su propia competencia literaria, Monaco sabe que no le puede dejar solo y, por tanto, le proporciona los elementos básicos del texto original, por un lado, a través de las palabras sucintas de Euriclea y, por otro, sirviéndose de las coreografías de la bailarina ${ }^{25}$.

En algunos momentos se utiliza el discurso directo, se cita entre comillas las palabras exactas y se ironiza con ellas utilizándolas de forma literal o sacándolas de su contexto con clara intención de burla o incluso de desprecio ante el enunciador original del discurso ${ }^{26}$. No se trata solo de citar a Homero, sino también - aumentando la polifonía - textos en los que se revisita el mito. Es el caso del poema de Cavafis (Monaco, 2016:104) ${ }^{27}$ en el que, por otros motivos y con otras intenciones al mito original, el poeta griego se centra en la importancia del largo viaje. Penélope, con clara intención burlona y desacralizadora, toma literalmente sus palabras: "'non aver fretta nel tuo viaggio!' Ulisse fretta non ne ha avuta di certo. Diecianni per tornare a casa da Troia" (Monaco, 2016:104).

\footnotetext{
${ }^{23}$ Para Butler (2007:350), la parodia es un ejercicio mimético de lo que se plantea como original con el objetivo de evidenciar que incluso lo considerado como original es también derivado. Esta estudiosa considera que se llega a la parodia con la creación de paradojas y contradicciones que permiten que se multipliquen las posibilidades de identidad, más allá de un rol que se repite siempre igual en el tiempo. En este sentido presenta su noción de "género performativo".

${ }^{24}$ Brumfit y Carter (1986:18) definen la competencia literaria como "an interesting combination of linguistic, sociocultural, historical and semiotic awareness".

${ }^{25}$ Para un análisis de estas coreografías, véase Martín-Clavijo (2017b).

${ }^{26}$ Sobre el discurso directo como vehículo de la ironía, véase el estudio de Barreras Gómez (2001-2002).

${ }^{27}$ En Penelopeide se establece un diálogo con la versión oficial de Ulises y otras versiones posthoméricas clásicas, además de la que nos traen Cavafis, Margaret Atwood y Safo. Un estudio de esta intertextualidad se lleva a cabo en Martín-Clavijo (2018).
} 
En la escena séptima, Euriclea, que se ha cubierto la cara con una máscara del héroe homérico, retoma también las palabras exactas de Ulises para ponerlas, a continuación, en contraste con lo que podría haber pensado en ese momento. Odiseo ha llegado a Ítaca y se pregunta por su mujer, por lo que habrá pasado en esos veinte años. El gran héroe finalmente se va a quedar solo ante Penélope y, en ese momento, el Ulises del gran ingenio no va a saber qué creer.

PENELOPE- (Col tono dell'Ade) Era arrivato, oggi si direbbe, in incognito. Il minimo per un furbacchione come lui. Voleva non solo prendere di sorpresa i Proci, fingendosi un vecchio debole e ignaro all'uso delle armi, ma voleva anche osservarmi, scoprire se lo avevo tradito, (Amaramente) se gli ero stata fedele.

EURICLEA- (Maschera di Ulisse) Non è sciupata. Non è deperita. Dovrebbe esserlo, dopo vent'anni, a piangere in attesa del ritorno del marito. (Breve pausa) (Riflette) La castità non giova alla bellezza delle donne. Che sia vero quel che si dice in giro?

PENELOPE- Poiché diffidava, io gli diedi corda. Fra tutti i monili, la sera in cui lo invitammo al banchetto, indossai l'unica collana che non apparteneva né alla mia dote né ai suoi regali. ( $S i$ cinge il collo di una collana di lapislazzuli e mette un fiore rosso fra i capelli)

EURICLEA- (Maschera di Ulisse) Sono davvero così cambiato o mi sono travestito molto bene? Sì credo sia questo. (Si pavoneggia) Vent'anni in un uomo non si notano. (Sospettoso) E quella collana di lapislazzuli? Non l'ho mai vista! Lo chiederò ad Euriclea (Monaco, 2016:119).

Evidentemente, Monaco a través de las palabras de Euriclea con la máscara del héroe, nos presenta en escena un Ulises un tanto insólito y se nos revela su sentir más profundo, se rescatan sus pensamientos, sus dudas, sus esperanzas en el ámbito personal, doméstico. Ya no se trata de un héroe, sino de un hombre.

Pero también la parodia se lleva a cabo al revocar algunos episodios de la Odisea, pero de forma aislada, desmontándolos y luego acompañándolos de un comentario o interpretación irónica caracterizada por un cambio de tono muy marcado; se pasa así del tono de Ítaca - serio, oficial, legitimado - al tono desde el Hades - profundamente desacreditador, soez, burlón.

Durante los largos años de ausencia, a Ítaca llegan las historias de las aventuras de Ulises, las que cuenta luego el mito homérico. De nuevo será Euriclea, desde el pasado, la que, como si se tratara de un narrador de historias y sirviéndose del tono de un cuento de hadas, trae a escena, aunque de manera muy resumida, prácticamente solo esbozadas, las historias más conocidas que vivió Ulises a la vuelta de Troya. Se trata de cinco fragmentos representativos de su largo viaje: los lotófagos, los cíclopes, las sirenas, Circe y Calipso. En total son dos páginas de aventuras coronadas con pocas palabras, eso sí, muy punzantes, de Penélope que, desde el presente, las reinterpreta y desacraliza:

EURICLEA- (Come un cantastorie, tono fiabesco) Dopo l'infuriare di una terribile tempesta Ulisse e i suoi compagni approdarono esausti sulle rive di un paese abitato da strane creature. I Lotofagi. I mangiatori di Loto. Chi si fosse nutrito di quelle piante avrebbe dimenticato ogni cosa. Ogni affanno ma anche ogni desiderio e avrebbe smarrito la via di casa...

PENELOPE- (Interrompendo, tono pratico, sdrammatizza) Balle! Quelli si son fatti delle canne (Monaco, 2016:116).

Al igual que los lotófagos se asimilan a fumadores de porros, Polifemo será "un oste che era stato accecato da un avventore perché gli aveva venduto del vino al metanolo" (Monaco, 2016:117) y las sirenas "prostitute di un bordello siciliano particolarmente raffinato, dove le ragazze erano esperte nel canto e si vestivano di piumaggi art deco" (Monaco, 2016:117). Para Penélope todas esas historias no tienen validez: "E dateci un taglio! Ora basta!!!Venite a Itaca da lontano, credete di dirmi chissà cosa su Ulisse e mi raccontate più o meno le stesse cazzate!" (Monaco, 2016:117).

Como vemos, ese lenguaje indecoroso y procaz hace bajar drásticamente a Ulises de su pedestal, al presentarle sin sus atributos heroicos más destacados. De esta manera, "lo cómico, desde el punto de vista del espíritu ortodoxo, adviene como resultado de una caída, deudora a su vez de la degradación física o moral del ethos del héroe" (López López, 2014:90). 
Como procedimiento para provocar la risa, la trasposición del tono consiste en pasar de hablar de algo serio a otra cosa profundamente trivial, superficial, sin transición alguna. $\mathrm{O}$ viceversa, pasar de una conversación no trascendental a una de vital importancia, pero sin resaltar el cambio, sin cesuras entre una temática y otra, sin transiciones ni nexos: de algo trágico, a lo trivial, de lo doméstico a lo solemne. Se rompe, de golpe, tanto con lo trágico como con lo cómico: se le quita seriedad a lo trágico y se carga de esta a lo cómico.

Las dos voces protagonistas en numerosas ocasiones no presentan distinción alguna entre la cultura alta y baja, entre los distintos códigos lingüísticos o registros; de hecho, en Penelopeide se mezclan expresiones cultas con otras vulgares, registros literarios cultos con otros cotidianos. Esta yuxtaposición de registros muy diferentes - rasgo típicamente postmoderno - crea una fuerte ironía. Pero no podemos olvidar que todo cambio de código indica a su vez un cambio de perspectiva $e$ incluso de identidad que no escapa al público/lector que aprecia claramente esa ruptura con las convenciones lingüísticas esperadas en una determinada situación. Como se ha estudiado desde las teorías sobre la ironía, esta surge a partir de la incongruencia ${ }^{28}$ en la forma en que se expresan las ideas a través de un juego con las expectativas.

A veces, Monaco no se sirve ni siquiera de las dos voces en escena, con una sola le basta, como se ve en este parlamento de Penélope donde esta nos da la versión oficial y, a continuación, su interpretación desde el presente:

Elena invece dicono che era uscita da un uovo, perché era figlia di Zeus, che aveva assunto le sembianze di un cigno per possedere sua madre nel sonno. Elena ci teneva molto a questa sua nascita. Non so in quanti ci credessero alla storia del cigno stupratore, ma contenta lei, e soprattutto suo padre... (Monaco, 2016:105).

Esta transposición de tono tan marcada resulta en determinadas ocasiones muy exagerada, llegando incluso a convertir una tragedia en un suceso trivial, quitándole todo el hierro que esta pudiera tener originariamente. Es el caso, por ejemplo, de la escena sexta en la que Penélope relata la historia de las criadas, en especial la de la joven Melanto quien, por ayudarla, sufrirá una violación en grupo por parte de los pretendientes de la señora de Ítaca:

PENELOPE- Melanto dalle belle gote non aveva neppure dodici anni quando la mandai a servire in tavola, per ascoltare i discorsi dei Proci e riferirmi delle loro mosse. Le ordinai di parlare male di me, così loro avrebbero più liberamente esposto i loro pensieri. Le sue grida, quando la possedettero in branco, le sento ancora nelle mie orecchie. E davanti agli occhi ho la scena di quando tornò da me, a riferirmi di ogni cosa, come le avevo ordinato. Tremava e la sua tunica era sporca di sangue! (Monaco, 2016:114).

Ante esta brutal narración de los hechos, Euriclea solo responde con un proverbio de lo más cotidiano, que significa que el que se aventura en una empresa debe saber aceptar las consecuencias: "Chi va al mulino s'infarina!" (Monaco, 2016:114). Se pasa de la tragedia al proverbio popular. Para Penélope, Euriclea tiene la "abitudine di sentenziare" (Monaco, 2016:115), siempre expresa con autoridad una opinión, una decisión sobre algo, en este caso, ante la narración de la violación de Melanto y de las otras criadas y luego su muerte, Euriclea solo dice del gran héroe griego: "La vendetta è un piatto che va servito freddo" (Monaco, 2016:115). Una venganza ¿propia de un héroe? Sí, continúa Euriclea con la máscara de Ulises: "Qui occorre una punizione esemplare. Telemaco, prendi la mia spada, sgozzale a tuo piacimento! (Breve pausa) Ah come dici? La spada è onorevole: impicchiamole. Buona idea, così non sporchiamo il pavimento che loro hanno appena lavato! (Ride di gusto)" (Monaco, 2016:122).

También Penélope, sirviéndose siempre de una fuerte intención paródica, arremete contra otras versiones en las que la mujer de Ulises ya no se propone como modelo de esposa fiel y paciente, sino todo lo contrario:

\footnotetext{
${ }^{28}$ Desde las teorías de la incongruencia se considera que el humor se basa en el descubrimiento de una realidad o un pensamiento que resulta incongruente con lo que se esperaba y, por lo tanto, se produce en la otra persona la sensación de que le han engañado, al no haber tenido en cuenta otras interpretaciones posibles. Sobre estas teorías véase, entre otros, Buckley (2005), Hurley et al. (2011) y Morreall (1983, 1987).
} 
PENELOPE- Volete sapere che si dice adesso, di me, qui? Le male lingue. Ora si dice gossip. Hanno inventato una bella storiella su di me e i Proci. I Proci erano i principi delle isole che facevano parte del regno di Itaca, Dulichio, Samo, Zacinto e Itaca stessa. Non meno di 129. Ed io, lussuriosa erotomane giacendo con loro, non è precisato se insieme o a turno, avrei generato il dio Pan. Il dio della passione sfrenata.

BALLERINA in a solo come dio Pan.

PENELOPE- Mi sembra un tantinello esagerato. Da non aver giaciuto con nessuno, nessuno per vent'anni a 129 in una volta sola! (Monaco, 2016:122).

Entonces, si Penélope no es ni un modelo de mujer sumisa y fiel, madre y esposa ejemplar, pero tampoco una lujuriosa erotómana, ¿quién es entonces?, ¿qué hay de verdad en el relato homérico de Penélope?

\section{De lo esperado a lo inesperado: Penélope, protagonista de su propio relato}

El cambio de óptica, de la mirada desde lo alto, desde el héroe a la de la mujer perennemente en segundo plano lleva a Patrizia Monaco a presentar una imagen de la protagonista ciertamente original. De esta manera, toma distancias del mito oficial y, alineándose con las ideas expuestas por importantes teóricas feministas subvierte el mito. Desde el primer momento, se nos muestra a una Penélope reivindicativa, para nada complaciente con el orden de las cosas, una mujer que se sirve del humor, sí, pero que no está de buen humor. La Penélope de Monaco arremete con fuerza contra las bases de la sociedad patriarcal $y$, utilizando las palabras de Simone de Beauvoir (1972:340), va contra el orden patriarcal, el derecho y su encarnación en un jefe:

En todo Olimpo hay un dios soberano, la peligrosa esencia viril debe concentrarse en un arquetipo del cual padre, marido o amantes no son más que inciertos reflejos. Resulta un tanto humorístico decir que el culto que rinden a este gran tótem es sexual...de su infancia y su ignorancia nace el respeto que otorgan las mujeres a los héroes y a las leyes del mundo masculino.

A este culto al hombre convertido en héroe, la mujer puede reaccionar sirviéndose de un arma muy potente, el humor, para entrar en la cabeza de Penélope, para acceder a su pensamiento. De esta manera, de figura pasiva, sumisa, pasa a ocupar un protagonismo activo en el relato. De nuevo, la dramaturga se enfrenta a la subversión de esa imagen tan habitual de Penélope para presentarnos otra con una identidad definida, propia. Desde el principio, se la sitúa en una genealogía que nada tiene que envidiar a otros héroes homéricos. No es una mujer cualquiera, "mia madre era una divinità marina, ed io quindi ero una semidea" (Monaco, 2016:105), es también hija de un rey. Pero, sobre todo, se trata de una mujer que tiene cabeza ${ }^{29}$, que intelectualmente está muy cerca del ingenio de su marido, que entiende lo que pasa a su alrededor $e$ intenta modificarlo con arreglo a unos objetivos muy claros; Penélope es una mujer fuerte e independiente que aprendió muy pronto "a cavarmela con le mie forze e a diffidare, sempre" (Monaco, 2016:106), que consigue mantenerse reina de Ítaca contra viento y marea, ella sola durante veinte largos años.

Al subrayar esas cualidades Patrizia Monaco convierte a Penélope en una mujer que puede servir de modelo en la actualidad, a pesar de que mantiene inalterados dos aspectos originales del mito muy atacados en otras versiones actuales: su proverbial paciencia y su amor por Ulises. La Penélope de Monaco es una mujer consciente de ello y así lo declara: "Non l'ho aspettato perché dovevo. L'ho atteso perché sapevo. Sapevo che era vivo. E perché l'amavo" (Monaco, 2016:124).

\section{A modo de conclusión}

Lo único que pretende el humor es que, por un instante, nos salgamos de nosotros mismos, nos marchemos de puntillas a unos veinte metros y demos una vuelta a nuestro alrededor

\footnotetext{
${ }^{29}$ De su inteligencia se burla Elena directamente: "Ma dicono [Ulisse] sia molto intelligente. Anche tu, pare. Buon per te, così potrai capire quello che ti dice. Io non ci riuscirei mai!” (Monaco, 2016:108).
} 
contemplándonos por un lado y por otro, por detrás y por delante, como ante tres espejos de una sastrería y descubramos nuevos rasgos y perfiles que no conocíamos. El humor es verle la trampa a todo, darse cuenta de por dónde cojean las cosas; comprender que todo tiene un revés, que todas las cosas pueden ser de otra manera (Mihura, 1998:304-5).

Así definía el humor el dramaturgo español Miguel Mihura. Para poder observar la realidad tenemos que tomar distancia de nosotros mismos y, así - desde todos los ángulos posibles, desde el derecho, pero también desde el revés, desde arriba y desde abajo - comprobar si realmente está bien hecha o, por el contrario, presenta imperfecciones. Eso es lo que lleva a cabo Patrizia Monaco con su Penelopeide: se sale del imaginario masculino para poder ver o imaginar las posibilidades que existen fuera de esa posición, más allá de la historia oficial legitimizada. Con el cambio de perspectiva, desde el centro a la periferia, Penélope se revela ciertamente inconformista, rebelde y crítica con la tradición; decidida a romper el orden establecido y mostrar todas sus grietas; convencida de que ha llegado la hora de acceder a la realidad sin filtros, aunque sea doloroso. Una realidad que no es tan compacta y uniforme como nos la han presentado durante siglos y cuya fragmentación múltiple es trágicamente humorística.

A través de la parodia del mito de Penélope no se busca la risa, más bien despertar a quienes leen el texto o acuden al teatro para ver la representación a la reflexión, a la duda, a la toma de conciencia y el cambio de actitud; seguramente también la dramaturga busca su complicidad, especialmente, pero no solo, de las mujeres. Y, además, garantiza la continuación del mito a través de una reinterpretación nueva que la acerque más al día de hoy.

\section{Referencias bibliográficas}

BARRERAS GÓMEZ, Asunción. El estudio de la ironía en el texto literario. Cuadernos de Investigación Filológica, 27-28, 2001-2002, pp.243-266.

BERGER, Peter L. Reediming Laughter: the Comic Dimension of Human Experience. Nueva York, Walter de Gruyter\& Co., 1997.

BILLINGSLEY, Amy. Laughing against Patriarchy: Humor, Silence, and Feminist Resistance. In: Philosophy Matters Prize Winning Essays, University of Oregon, 2013. [https://pages.uoregon.edu/uophil/files/Philosophy_Matters_Submission_Marvin_Billingsley.pdf - acceso el 12 diciembre 2019].

BRUMFIT, Christopher; CARTER, Ron A. Literature and Language Teaching. Oxford, Oxford University Press, 1986.

BUCKLEY, Frank H. The Morality of Laughter. A Serious Look at the Meaning of Laughter. Anna Arbor, University of Michigan Press, 2005.

BUTLER, J.; SOLEY, P. Deshacer el género. Barcelona, Paidós, 2006.

BUTLER, Judith. El género en disputa. El feminismo y la subversión de la identidad. Barcelona, Paidós, 2007.

CHAUVIN, Danièle. Hypertextualité et mythocritique. In: CHAUVIN, Danièle; SIGANOS, André; WALTER, Philippe (dir.). Questions de mythocritique. Dictionnaire. París, Éditions Imago, 2005, pp.175-176.

CIPLIJAUSKAITE, Biruté. La novela femenina contemporánea (1970-1985). Barcelona, Anthropos, 1994.

CIXOUS, Hélène. La risa deMedusa. Ensayos sobre la escritura. Barcelona, Anthropos, 1995.

CIXOUS, Helene. Castration or Decapitation? Signs, v. 7, n. 1, 1981, pp.41-55.

DE BEAUVOIR, Simone. El segundo sexo. Vol. I, Buenos Aires, Siglo XXI, 1972.

ECO, Umberto. El nombre de la rosa. Barcelona, Mondadori, 2010.

GARCÍA ROMERO, Fernando. Observaciones sobre el tratamiento del mito de Ulises en el teatro español contemporáneo. Analecta Malacitana 20, 1997, pp.513-526.

GENTILE, Brigidina. La otra Penélope. Antología de mujeres escritoras de la lengua española. Sevilla, Arcibel, 2011. 
GÓMEZ JIMÉNEZ, Miguel. Humanización e ironía en Circe en el relato de Lourdes Ortiz. AnMal, XXXV, 1-2, 2012, pp.99-118.

HURLEY, Matthew; DENNETT, Daniel; ADAMS, Reginald. Inside Jokes: Using Humor to Reverse-Engineer the Mind. Cambridge, Massachusetts, MIT Press, 2011.

HUTCHEON, Linda. The Politics of Postmodernism. London, New York, Routlegde, 1989.

HYERS, Conrad. The Spirituality of Comedy. Comic Heroism in a Tragic World. New Brunswick, Transaction Publishers, 1996.

IRIGARAY, Luce. An Ethics of Sexual Difference. Gill. Ithaca, NY, Cornell University Press, 1993.

IRIGARAY, Luce. This Sex Which is not One. Ithaca, NY, Cornell University Press, 1985.

JULIANO, Dolores. Excluidas y marginales. Una aproximación antropológica. Madrid, Cátedra, 2004.

KATZ, Marylin A. Penelope's Renown. Meaning and Indeterminacy in the Odyssey. Princeton N. J., Princeton Univ. Press, 1991.

LASSO DE LA VEGA, José. La presencia del mito griego en nuestro tiempo. Anejos de Gerión II. Homenaje a Santiago Montero. Madrid, 1989, pp.99-114.

LIPOVETSKY, Gilles. La era del vacío. Ensayos sobre el individualismo contemporáneo. Barcelona, Anagrama, 1986.

LÓPEZ LÓPEZ, Carmen María. Odiseo a través de la parodia. Desmitificación e ironía de una Ítaca nostálgica en Prometeo de Pérez de Ayala y ¿Por qué corres, Ulises? de Gala. Panta Rei, 2014, pp.71-95.

MACTOUX, Marie-Madeleine. Penélope, légende et mythe. París, Les Belles Lettres, 1974.

MARTÍN-CLAVIJO, Milagro. Diálogo intertextual en la Penelopeide de Patrizia Monaco. Cuadernos de Filología Italiana, 25, 2018, pp. 233-246.

MARTín-CLAVIJO, Milagro (ed.). Parole inquiete. L'opera drammaturgica di Patrizia Monaco. Sevilla, Benilde, 2017a.

MARTÍN-CLAVIJO, Milagro. Un altro narratore: le ballerine nella drammaturgia di Patrizia Monaco. In: MARTín-CLAVIJO, Milagro (ed.). Parole inquiete. L'opera drammaturgica di Patrizia Monaco, Sevilla Benilde, 2017b, pp.81-99.

MARTÍN-CLAVIJO, Milagro. Penelopeide de Patrizia Monaco: la odisea de Penélope a escena. In: O libro do Tempo: Escritas e reescritas. Teatro Greco-latino e suarecepçao II. Coimbra, Coimbra University Press, 2016a, pp.367-380.

MARTÍN-CLAVIJO, Milagro. L'altro volto della violenza. In: MONACO, Patrizia. Donne in lotta. Roma, Aracne, 2016b, pp.125-137.

MIHURA, Miguel. Mis memorias. Madrid, Temas de hoy, 1998.

MONACO, Patrizia. Penelopeide. In: MONACO, Patrizia. Donne in lotta. Roma: Aracne, 2016, pp.99-124.

MORANO, Ciriaca. El resurgir de lo mítico en la literatura contemporánea: diversos procedimientos de acceso al mito. Faventia, 4, 1982, pp.77-93.

MONREALL, John. Comic Relief: A Comprenhensive Philosophy of Humor. Malden MA, Wiley and Sons Ltd., 2009.

MONREALL, John. Comedy, Tragedy, and Religion. Albany NY, Albany State University of New York Press, 1999.

MONREALL, John. Funny Ha-Ha, Funny Strange and Other Reactions to Incongrunity. In: MONREALL, John (ed.). The Philosophy of Laughter and Humor. New York, Suny, 1987, pp.188-207.

MONREALL, John. Taking Laughter Seriously, Albany, State University of New York Press, 1983.

OCHOA SANTOS, Miguel Gabriel. Mito, filosofía y literatura en la modernidad. Madrid, Plaza y Valdés, 2003.

PISCITELLI, Adriana. Re-criando a (categoria) mulher?. In: A prática feminista e o conceito de gênero, textos didáticos, n.48, 2002, pp.7-42. 
SANDIAS, Maria. Prologo. In: MARTÍN-CLAVIJO, Milagro (ed.). Parole inquiete. L'opera drammaturgica di Patrizia Monaco. Sevilla Benilde, 2017, pp.11-18.

TROVATO, Roberto. Due rivisitazioni ironiche e fantasiose di alcuni miti della letteratur aoccidentale. In: MARTíN-CLAVIJO, Milagro (ed.). Parole inquiete. L'opera drammaturgica di Patrizia Monaco. Sevilla Benilde, 2017, pp.111-126.

TROVATO, Roberto. Condominio mitologico di Patrizia Monaco: una casa del duemila con vista sul passato. In: O libro do Tempo: Escritas e reescritas. Teatro Greco-latino e suarecepçao II. Coimbra, CoimbraUniversityPress, 2016a, pp.351-365.

TROVATO, Roberto. La verità del personaggio. In: MONACO, Patrizia. Donne in lotta. Roma, Aracne, 2016b, pp.9-28.

TROVATO, Roberto. Dalla tela alla scena. Analisi drammaturgica di Sherazade va in Occidente di Patrizia Monaco. Revista Internacional de Culturas \& Literaturas, 2014, pp.1-13.

TROVATO, Roberto. La scrittura come vita e come gioco. Il teatro di Patrizia Monaco. In: MARTíN-CLAVIJO, Milagro et al. (ed.). Las voces de las Diosas. Sevilla, Arcibel, 2012, pp.1321-1345.

ZIV, Avner. The Influence of Humorous Atmosphere on Divergent Thinking. Contemporary Educational Psychology, 1983, v. 8, pp.68-75. 